\title{
Evaluation of SUVlean consistency in FDG and PSMA PET/MR with Dixon-, James-, and Janma-based lean body mass correction
}

\author{
Jun Zhao ${ }^{1 *+}$ (D) Qiaoyi Xue ${ }^{2 \dagger}$, Xing Chen ${ }^{1}$, Zhiwen You ${ }^{1}$, Zhe Wang ${ }^{2}$, Jianmin Yuan ${ }^{2}$, Hui Liu ${ }^{2}$ and Lingzhi Hu ${ }^{2}$
}

\author{
* Correspondence: petcenter@126. \\ com \\ †un Zhao and Qiaoyi Xue \\ contributed equally to this work. \\ ${ }^{1}$ Department of Nuclear Medicine, \\ Shanghai East Hospital, Tongji \\ University School of Medicine, \\ Shanghai, China \\ Full list of author information is \\ available at the end of the article
}

\begin{abstract}
Purpose: To systematically evaluate the consistency of various standardized uptake value (SUV) lean body mass (LBM) normalization methods in a clinical positron emission tomography/magnetic resonance imaging (PET/MR) setting.

Methods: SUV of brain, liver, prostate, parotid, blood, and muscle were measured in $90{ }^{18} \mathrm{~F}-\mathrm{FDG}$ and $28{ }^{18} \mathrm{~F}$-PSMA PET/MR scans and corrected for LBM using the James, Janma (short for Janmahasatian), and Dixon approaches. The prospective study was performed from December 2018 to August 2020 at Shanghai East Hospital. Forty dual energy X-ray absorptiometry (DXA) measurements of non-fat mass were used as the reference standard. Agreement between different LBM methods was assessed by linear regression and Bland-Altman statistics. SUV's dependency on BMI was evaluated by means of linear regression and Pearson correlation.

Results: Compared to DXA, the Dixon approach presented the least bias in LBM/ weight\% than James and Janma models (bias $0.4 \pm 7.3 \%,-8.0 \pm 9.4 \%$, and $-3.3 \pm 8.3 \%$ respectively). SUV normalized by body weight (SUVbw) was positively correlated with body mass index (BMI) for both FDG (e.g., liver: $r=0.45, p<0.001$ ) and PSMA scans $(r=0.20, p=0.31$ ), while SUV normalized by lean body mass (SUVlean) revealed a decreased dependency on BMI $(r=0.22,0.08,0.14, p=0.04,0.46,0.18$ for Dixon, James, and Janma models, respectively). The liver SUVbw of obese/overweight patients was significantly larger $(p<0.001)$ than that of normal patients, whereas the bias was mostly eliminated in SUVlean. One-way ANOVA showed significant difference $(p<0.001)$ between SUVlean in major organs measured using Dixon method vs James and Janma models.
\end{abstract}

Conclusion: Significant systematic variation was found using different approaches to calculate SUVlean. A consistent correction method should be applied for serial PET/ MR scans. The Dixon method provides the most accurate measure of LBM, yielding the least bias of all approaches when compared to DXA.

Keywords: SUV, Lean body mass, PET/MR (c) The Author(s). 2021 Open Access This article is licensed under a Creative Commons Attribution 4.0 International License, which permits use, sharing, adaptation, distribution and reproduction in any medium or format, as long as you give appropriate credit to the original author(s) and the source, provide a link to the Creative Commons licence, and indicate if changes were made. The images or other third party material in this article are included in the article's Creative Commons licence, unless indicated otherwise in a credit line to the material. If material is not included in the article's Creative Commons licence and your intended use is not permitted by statutory regulation or exceeds the permitted use, you will need to obtain permission directly from the copyright holder. To view a copy of this licence, visit http://creativecommons.org/licenses/by/4.0/. 


\section{Introduction}

The unique benefits of integrated positron emission tomography/magnetic resonance imaging (PET/MR), including comprehensive contrast mechanisms and seamless fusion of morphology and function, are driving adoption and exploration in both the clinical and research domains. Because of the reduced radiation dose of PET/MR versus PET/CT, and the increasing utilization of non-FDG (fluorodeoxyglucose) tracers, such as PSMA (prostate-specific membrane antigen) and DOTATATE $[1,2]$, serial PET/MR scans are becoming more desired for re-staging and treatment response evaluation for oncological patients. Patients might present dramatic physiological variation in terms of body weight throughout the course of treatment, requiring serial PET scans to maintain high standards for consistent and accurate quantitation [3].

In PET studies, standardized uptake value (SUV) is the most widely used semiquantitative measurement of radiotracer uptake, essential for diagnosis and treatment response assessment. SUV is defined as the radioactivity in a region of interest (ROI) normalized to the total injected dose and body weight of the patient [4]. Although SUV normalized to body weight (SUVbw) is the most popular metric in today's clinical setting, Zasadny and Wahl found that it is highly dependent on patient weight and body fat content [5]. A potential cause of inconsistency is that white adipose tissue minimally uptakes radiotracer but contributes to overall body weight. SUVbw is occasionally overestimated (especially for obese subjects) and can lead to systematic bias for serial scans of patients with multiple follow-ups throughout the course of treatment. Many studies have investigated methods to improve normalization factors of SUV to account for more consistent quantitation across a wide range of body mass indices (for example, BMI $=$ weight $/$ height $^{2}$ ). The most widely adopted approach is to use lean body mass (LBM) instead of body weight to offset the systematic bias caused by white adipose tissue [5]. This corrected SUV is often referred to as SUVlean or SUL. SUVlean has been recommended by PERCIST and has been widely accepted in clinical and research studies [6, 7].

Over the past decades, various predictive models have been established to estimate LBM, taking factors such as body weight, height, sex, and/or age into account. Some of these models have been translated into PET imaging to calculate SUVlean in the clinical setting [5, 8-10]. Among them, James equation [11] is the most widely used model for SUV correction and has been implemented in a variety of commercially available PET/CT and PET/MR scanners. However, a recent study has shown that James equation might be prone to significant inaccuracy when a patient's BMI exceeds a critical value (approximately 43 for men and 37 for women) [12]. An improved model proposed by Janmahasatian et al. [13] was adopted in some recent studies [12, 14] to improve the SUV consistency for patients with high BMI. However, even though this model-based LBM estimation was derived from extensive clinical data containing a large patient cohort, there are still concerns that the predictive formulae may cause substantial errors at the individual level. For instance, two patients with the same weight and height would exhibit identical LBM values but may present significantly different body fat composition.

New LBM estimation approaches based on direct measurement using CT or MR from PET/CT and PET/MR [15-18] are believed to be more reliable than model-based LBM methods $[14,19,20]$. For PET/MR imaging, the current state of the art MR-based attenuation correction (MRAC) utilizes a Dixon sequence to generate water/fat images [21] and such data could be readily utilized to obtain personalized calculation of LBM. 
The Dixon approach was recently suggested and validated in a pilot study, where Jochimsen et al. reported an initial attempt to normalize SUV with the Dixon-based water/fat fraction [22]. Good reproducibility and robust LBM measurement using the Dixon method was later reported by Rausch et al. [23].

Furthermore, it would be challenging to conduct an evaluation of SUVlean accuracy without validating these methods for LBM calculation against the current clinical reference standards [24]. One approach for validating and comparing different SUV normalization models is to utilize reference standard measurements of LBM [25] using well-established technology $[19,26]$. There are many ways to measure body fat and its distribution [27, 28]. For instance, dual energy X-ray absorptiometry (DXA) utilizes different attenuation coefficient of fat and soft tissue to obtain a patient-specific fat fraction [27, 29]. DXA has been reported to be more accurate than density-based methods and features good repeatability of regional fat fraction obtained by cropping the projected 2D coronal image [30].

Although a few recent studies have reported good reproducibility of the Dixon method [23] and good agreement between Dixon and DXA measurements of body fat [17, 31, 32], the robustness of PET SUV corrected by the Dixon method has not been well evaluated. In addition, because of the broad selection of methods to calculate LBM for SUVlean, there is an immediate need for comparative evaluation of the consistency and limitation across these methods for SUVlean calculations. The purpose of the present work is to systematically evaluate the accuracy of different LBM estimation methods, using DXA as a reference standard, and to investigate the consistency of various SUVlean calculations in a clinical setting. SUVlean measurements derived from Dixon images, as well as with James and Janma (short for Janmahasatian) LBM models, were compared in two patient cohorts of ${ }^{18} \mathrm{~F}$-FDG and ${ }^{18}$ F-PSMA PET/MR studies, respectively. To our knowledge, this is the first study to evaluate these three SUVlean methods in both an FDG and PSMA PET/MR cohort.

\section{Materials and methods}

\section{Patient population}

Patients $(N=118)$ were recruited for clinical PET/MR scans from December 2018 to August 2020 at Shanghai East Hospital for suspected or known malignancies. Among them, 90 underwent ${ }^{18} \mathrm{~F}$-FDG PET/MR scans and 28 underwent ${ }^{18} \mathrm{~F}$-PSMA PET/MR scans. Forty out of 118 patients were enrolled in a same day DXA scan for body fat measurement. Patient weight ranged from 37 to $103 \mathrm{~kg}$ and BMI ranged from 14.53 to 32.45 . Patients with metal implant and claustrophobia to MRI were excluded in this study. The study design is summarized in Fig. 1 and detailed information of the patients is provided in Table 1. The study protocol was reviewed and approved by institutional review board (IRB), and written informed consent was obtained from each patient.

\section{PET/MR image acquisition}

Whole-body PET/MR scans were performed on a hybrid PET/MR (uPMR 790, UIH, Shanghai, China), which consisted of a 3.0T MR and PET system with a transverse field of view of $60 \mathrm{~cm}$ and axial field of view of $32 \mathrm{~cm}$. The PET system comprises 112 rings, each containing $70015.5 \times 2.76 \times 2.76 \mathrm{~mm}^{3}$ LYSO crystals [33]. The PET system quality control was performed on a daily basis. All patients were requested to fast for at least $6 \mathrm{~h}$ before the injection of the radioactive tracer. For the FDG study, patients were 


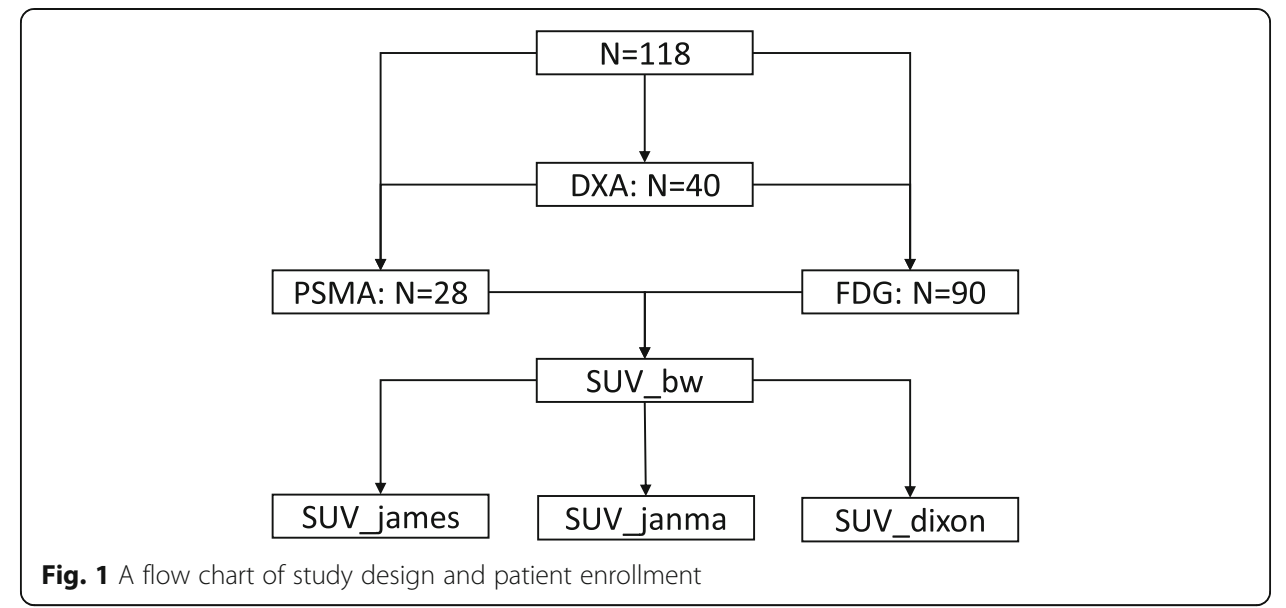

injected with $221 \pm 50 \mathrm{MBq}$ (or $0.096 \pm 0.017 \mathrm{mCi} / \mathrm{kg}$ ) of ${ }^{18} \mathrm{~F}-\mathrm{FDG}$ and rested in a quiet preparation room for about $1 \mathrm{~h}$. For the PSMA study, patients were injected with $314 \pm$ $73 \mathrm{MBq}$ of ${ }^{18} \mathrm{~F}$-PSMA-1007 and rested for about $2 \mathrm{~h}$.

Images were acquired using the clinical PET/MR protocol at Shanghai East Hospital. During the PET scan, a 2-point Dixon-based water-fat separation imaging sequence was performed simultaneously using a 3D T1-weighted gradient echo sequence with compressed sensing $(\mathrm{TE}=2.24 \mathrm{~ms}, \mathrm{TR}=4.91 \mathrm{~ms}$, flip angle $=10$, echo train length $=30, \mathrm{FOV}=549 \times$ 384 , matrix $=256 \times 329$, slice thickness $=2 \mathrm{~mm}$, slice spacing $=2 \mathrm{~mm}$, transverse plane). The PET/MR MRAC map was generated by segmenting the Dixon images into water, fat, lung, and air and assigning attenuation coefficients of $0.096,0.08,0.032$, and $0 \mathrm{~cm}^{-1}$, respectively. Representative images of PET/MR FDG and PSMA are shown in Figs. 2 and 3 respectively.

\section{DXA image acquisition}

DXA images were obtained using a dual-energy X-ray absorptiometry (DXA) (Lunar Prodigy, GE, Madison, USA) and the body composition was analyzed using vendorprovided software (enCORE, GE, Madison, USA). Since the PET/MR scan coverage was from skull to the upper thigh, the ROI of the DXA images were adjusted to match the axial coverage as the PET/MR image to calculate the total mass and fat mass.

Table 1 Characteristics of recruited patients

\begin{tabular}{llll}
\hline & FDG & PSMA & DXA \\
\hline$N$ & $48 F, 42 \mathrm{M}$ & $28 \mathrm{M}$ & 2 FF, 20M \\
Age & $58 \pm 13(17 \sim 91)$ & $70 \pm 7(56 \sim 89)$ & $60 \pm 12$ \\
Weight $(\mathrm{kg})$ & $63 \pm 14.4(37 \sim 103)$ & $70.7 \pm 8.4(54 \sim 87)$ & $64.7 \pm 12.6$ (43 94) \\
BMl & $23.11 \pm 4.54(14.5 \sim 32.5)$ & $24.47 \pm 2.55(18.7 \sim 28.3)$ & $23.47 \pm 3.5(15 \sim 31)$ \\
Height $(\mathrm{cm})$ & $165 \pm 7(150 \sim 183)$ & $170 \pm 5(162 \sim 180)$ & $165 \pm 7$ (152 180) \\
Time $(\mathrm{min})$ & $72 \pm 14$ & $141 \pm 18$ & $/$ \\
Dose $(\mathrm{mCi} / \mathrm{kg})$ & $9.6 \pm 1.7 \%$ & $12.1 \pm 3.1 \%$ & $/$ \\
Dose $(\mathrm{MBq})$ & $221 \pm 50$ & $314 \pm 73$ & $/$ \\
\hline
\end{tabular}

$B M I$ body mass index, FDG fluorodeoxyglucose, PSMA prostate-specific membrane antigen 


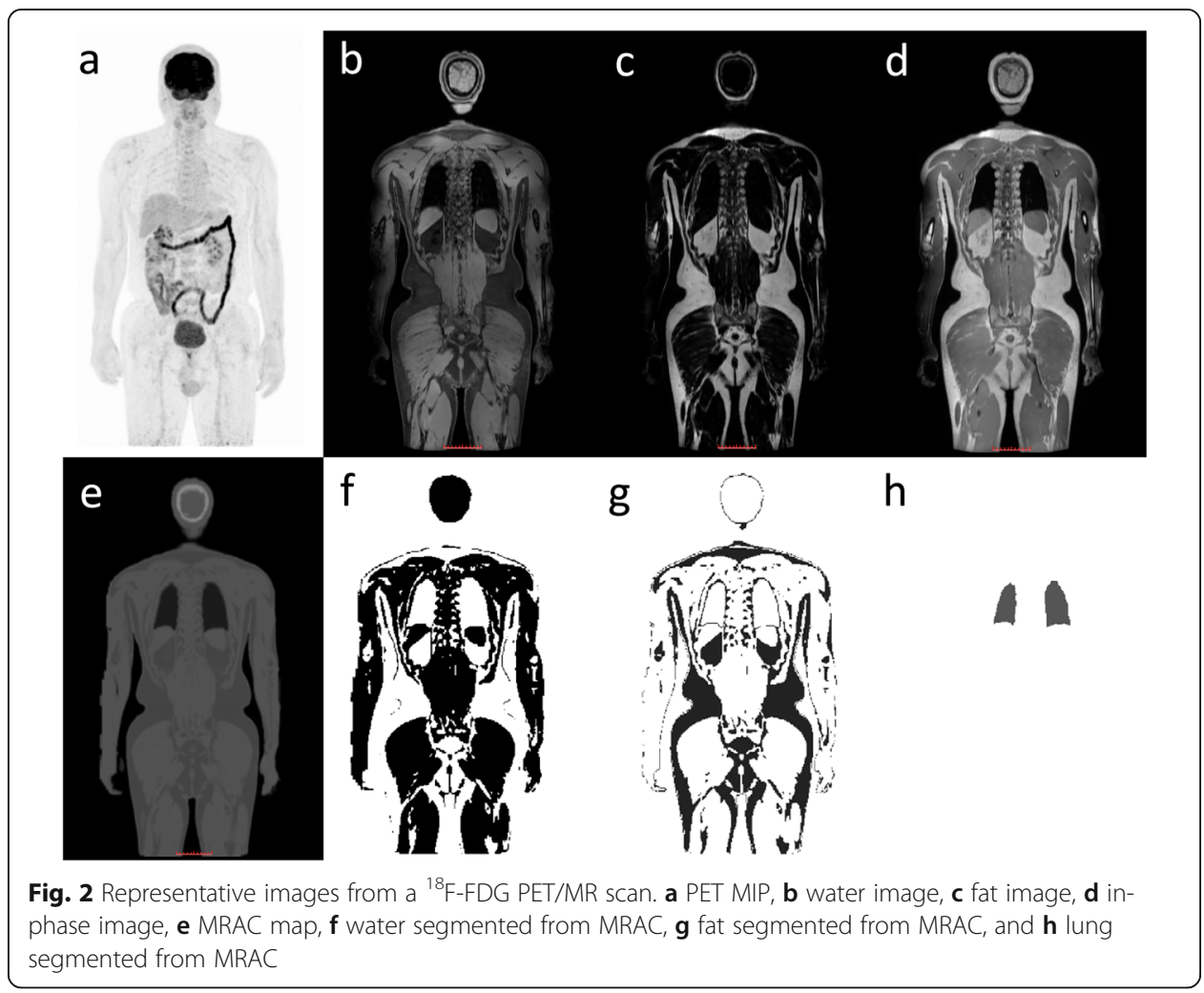

\section{LBM calculation}

The total volume of water, fat, lung, and air were obtained from the Dixon MRAC images by multiplying the total number of voxels by the voxel volume for each compartment. We first compared, using linear regression, the MRAC fat and water volumes with the mass derived from DXA analysis to assess the agreement between the two measurements. Population-based water and fat density were derived by using a linear fit of the MRAC volume versus the measured water and fat mass from DXA.

Model-based LBM were calculated using James equation and Janma equation respectively,

where:

$$
\text { LBWJanma }=\left\{\begin{array}{c}
9270 * \mathrm{BW} / 6680+216 * \mathrm{BMI}, \text { Men } \\
9270 * \mathrm{BW} / 8780+244 * \mathrm{BMI}, \text { Women }
\end{array}\right.
$$

and

$$
\text { LBWJames }=\left\{\begin{array}{c}
1.1 * \mathrm{BW}-128 *\left(\frac{\mathrm{BW}}{\text { height }}\right)^{2}, \text { Men } \\
1.07 * \mathrm{BW}-148 *\left(\frac{\mathrm{BW}}{\text { height }}\right)^{2}, \text { Women }
\end{array}\right.
$$

where BW is the body weight and LBWjanma/james are the lean body mass calculated by Janma and James equation. The results were compared with the direct measurement result from DXA as the reference standard. 


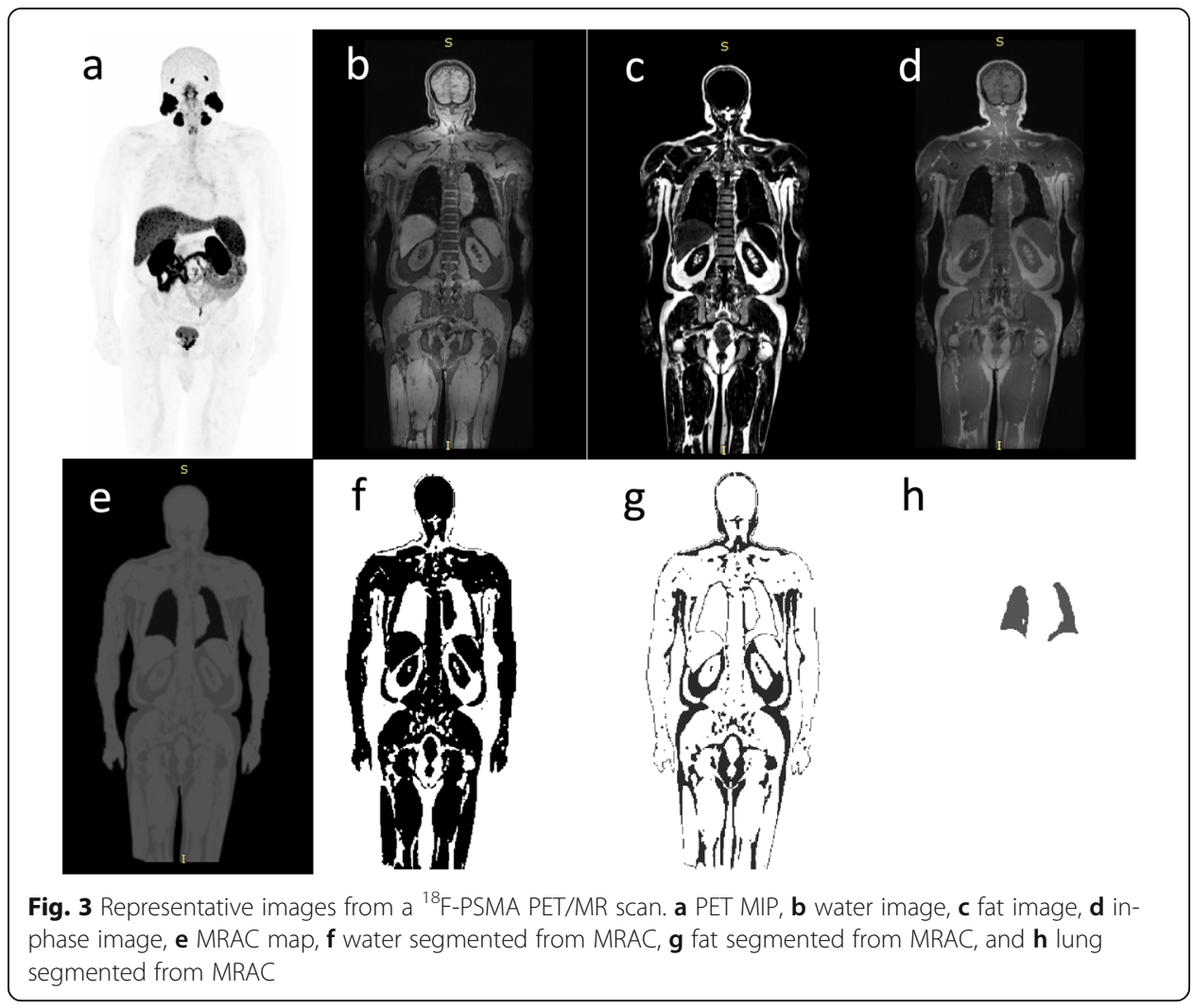

\section{PET reconstruction and SUV measurements}

All PET reconstructions and image analysis were performed on the vendor-provided workstation (uPMR 790, UIH, Shanghai, China). The PET images were reconstructed using the ordered subset expectation maximization (OSEM) algorithm (FOV $=600$ $\mathrm{mm}$, iteration $=2$, subsets $=20$, Gaussian filter with FWHM $=4 \mathrm{~mm}$, matrix size $=$ 150). The radioactivity of the major organs was measured by drawing ROIs on the workstation. Specifically, the radioactivity of the liver was obtained by placing a 3-cm diameter spherical ROI in the right hepatic lobe avoiding major vessels/lesions according to the PERCIST criteria [6]. The radioactivity of the blood pool was obtained by placing a $1-\mathrm{cm}$ diameter spherical ROI in the left ventricle, and the muscle radioactivity was obtained from the right thigh. Brain radioactivity in the FDG studies was obtained by thresholding out the whole brain using an in-house algorithm which was then subsequently validated by visual inspection. Prostate and parotid glands in the PSMA studies were detected by a thresholding tool available in the workstation software. SUVpeak and SUVmean of lymph node metastasis with avid PSMA uptake were measured by the same tool. SUVpeak was defined as the average value within a $1 \mathrm{~cm}^{3}$ volume around the SUVmax.

SUVbw was calculated by the default settings in the workstation as:

$$
\mathrm{SUVbw}=\frac{\text { radioactivity in } \mathrm{ROI}(\mathrm{kBq} / \mathrm{ml})}{\text { injected dose }(\mathrm{MBq}) * \text { decay factor } / \text { bodyweight }(\mathrm{kg})}
$$

where decay factor $=\exp \left(-0.693^{*}\right.$ wait time/radionuclide half-life $)$. 
SUVlean calculated using Dixon, James, and Janma approaches were denoted as SUV_dixon, SUV_james, and SUV_janma, respectively.

SUV_dixon was calculated as:

$$
\mathrm{SUV} \_ \text {dixon }=\mathrm{SUVbw} * \frac{\text { water mass }}{\text { water mass }+ \text { fat mass }+ \text { lung mass }}
$$

where water and fat mass were derived from the Dixon MRAC images.

SUV_james was calculated as:

$$
\text { SUV_james }=\text { SUVbw } * \text { LBWjames/bodyweight. }
$$

Finally, SUV_janma was calculated as:

$$
\text { SUV_janma }=\text { SUVbw } * \text { LBWjanma } / \text { bodyweight. }
$$

\section{Statistical analysis}

LBM calculated from Dixon, James, and Janma approaches were compared with the reference standard DXA calculations. Pearson correlation, paired $t$ tests, and Bland-Altman analysis were used to evaluate the measurement accuracy of different LBM methods. Scatter plots with linear regression were used to determine the relationship between SUVlean and BMI (supplementary material). Linear regression and Pearson correlation were used to assess the dependency of SUVbw and SUVlean on BMI. One-way ANOVA was used to check agreement between different SUV normalization methods. A Kolmogorov-Smirnov test (KS test) was used to check the normal assumption of the data before performing $t$ tests and ANOVA. All statistical analysis was performed in Matlab 2018b (MathWorks, Natick, MA, USA) and GraphPad Prism 8.0.2 (GraphPad Software, CA, USA).

\section{Results}

The KS test showed that the LBM fraction calculated using Dixon, James, Janma, and DXA as well as the BMI and SUV values all followed normal distribution.

\section{DXA vs Dixon}

The average body weight for the 20 female subjects was $58.65 \pm 8.70 \mathrm{~kg}$ and the average body weight for the 20 male subjects was $70.72 \pm 12.93 \mathrm{~kg}$. The average BMI for women was $22.57 \pm$ 3.18 and average BMI for men was $24.37 \pm 3.51$. The mean non-fat mass of the head-to-thigh region obtained in DXA was $30.14 \pm 3.90 \mathrm{~kg}$ for women and $43.47 \pm 7.86 \mathrm{~kg}$ for men. The corresponding total water volume obtained by the Dixon technique was $244.53 \pm 3.21 \mathrm{~L}$ for women and $344.92 \pm 5.67 \mathrm{~L}$ for men. The slope from the linear regression was 0.78 and 1.26 for fat and water, with $r^{2}=0.849$ and 0.915 respectively, suggesting excellent agreement between the measurements of DXA and Dixon (Fig. 4a). To convert MRI-measured volumes to weight in the recruited patient population, lung volumes were taken into account for multi-parameter linear regression, yielding coefficients (densities) of $0.79,1.23$, and 0.20 for fat, water and lung respectively. Using the derived tissue density, the fat and water mass was determined as $17.38 \pm$ $5.05 \mathrm{~kg}$ and $33.50 \pm 6.84 \mathrm{~kg}$ from the Dixon images. The Bland-Altman plot of fat fraction and water mass fraction are shown in Fig. 4b. The bias was 0.76 and 0.39 for water fraction and fat fraction respectively, and all points, except for one, fell into a confidence interval of two standard deviations. 


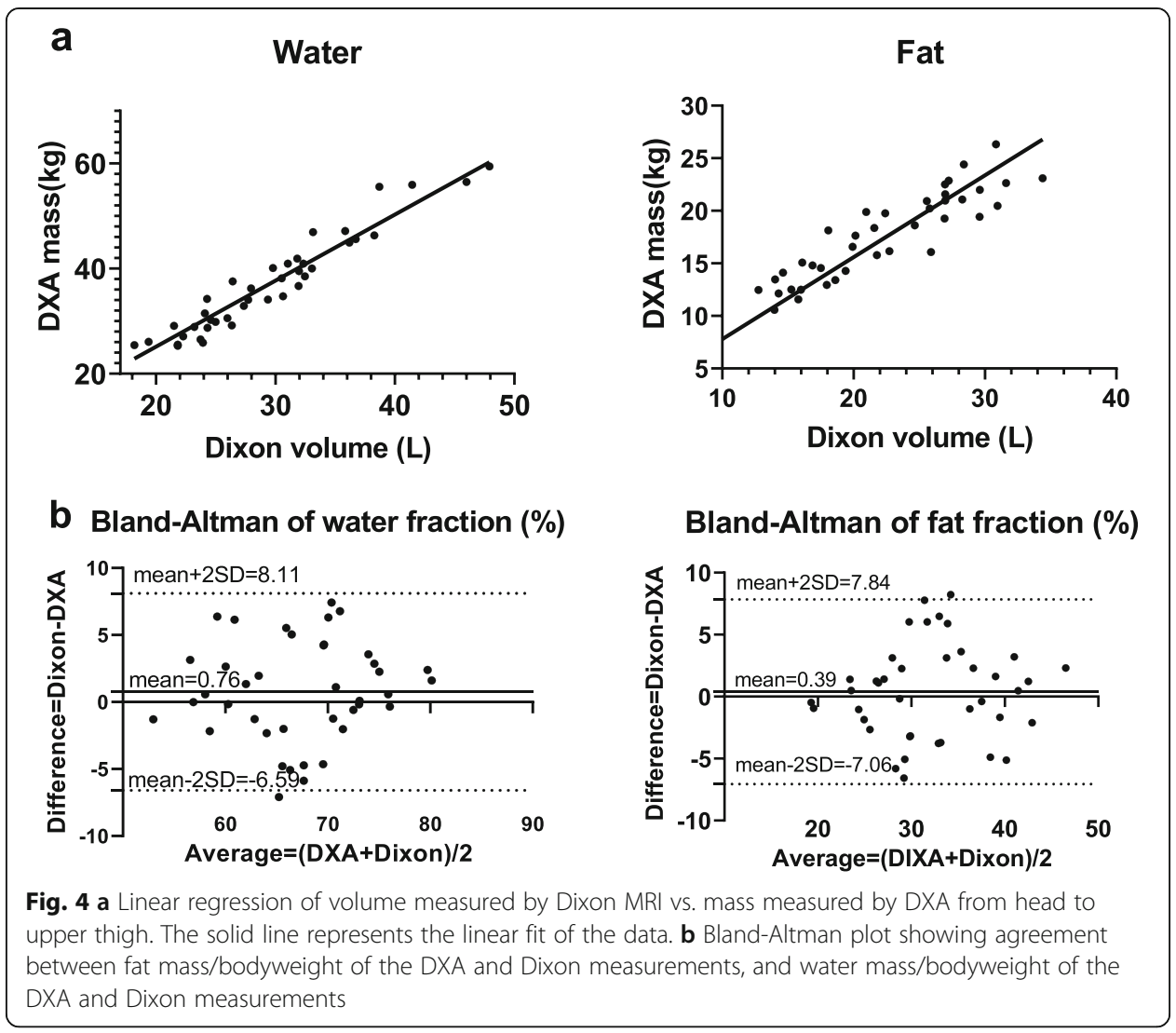

\section{LBM fraction}

The measured LBM fraction using DXA were $63.01 \pm 3.91 \%, 73.37 \pm 3.71 \%$, and 68.19 $\pm 6.43 \%$ for females, males, and all patients respectively. As summarized in Table 2, LBM fraction calculated using Dixon, James model, and Janma model were measured to be $62.68 \pm 5.74 \%, 73.59 \pm 4.82 \%$, and $65.08 \pm 3.67 \%$ for female patients; $71.22 \pm$ 4.59\%, $78.80 \pm 4.74 \%$, and $77.95 \pm 5.45 \%$ for male patients; and $66.95 \pm 6.71 \%, 76.199 \pm$ $5.406 \%$, and $71.56 \pm 7.97 \%$ for all patients respectively. Good correlation was found between Dixon LBM and DXA LBM in all groups. Paired $t$ tests showed that LBM fraction calculated by James and Janma were significantly different from the DXA results $(p<0.05)$ in all groups, whereas Dixon LBM was not significantly different from DXA in the female group and the all-gender group. Dixon had the smallest bias and strongest correlation with DXA, suggesting that the Dixon method offers the most accurate measurement of LBM. Both the James and Janma model tend to overestimate LBM for all patients. James model yielded the largest bias when compared with the DXA measurement, especially for female, where LBM was overestimated by $10 \%$.

\section{SUV in FDG study}

Linear regression between FDG SUVbw and SUVlean calculated using different approaches of LBM are plotted in supplementary material and the quantitative statistical results are summarized in Table 3. Pearson correlation between SUVbw and BMI was greater than that of SUVlean in all tissues and was found to be significantly correlated 
Table 2 LBM calculated using the Dixon, James, and Janma models compared with DXA as the reference standard

\begin{tabular}{|c|c|c|c|c|c|}
\hline (Unit: $100 \%)$ & & Mean + SD & Bias $\pm 2 \mathrm{SD}$ & Paired $t$ test & Correlation with DXA \\
\hline \multirow[t]{3}{*}{ Female, $N=20,63.01 \pm 3.91$} & Dixon & $63.04 \pm 5.73$ & $-1.14 \pm 7.84$ & 0.217 & 0.718 \\
\hline & James & $73.59 \pm 4.82$ & $-10.59 \pm 6.79$ & $<0.001$ & 0.707 \\
\hline & Janma & $65.08 \pm 3.67$ & $-2.07 \pm 5.66$ & 0.005 & 0.721 \\
\hline \multirow[t]{3}{*}{ Male, $N=20,73.37 \pm 3.71$} & Dixon & $71.50 \pm 4.56$ & $2.02 \pm 5.27$ & 0.003 & 0.809 \\
\hline & James & $78.80 \pm 4.74$ & $-5.44 \pm 8.95$ & $<0.001$ & 0.446 \\
\hline & Janma & $77.95 \pm 5.45$ & $-4.59 \pm 9.75$ & $<0.001$ & 0.468 \\
\hline \multirow[t]{3}{*}{ All, $N=40,68.19 \pm 6.43$} & Dixon & $67.27 \pm 6.67$ & $0.44 \pm 7.30$ & 0.460 & 0.853 \\
\hline & James & $76.20 \pm 5.41$ & $-8.01 \pm 9.36$ & $<0.001$ & 0.694 \\
\hline & Janma & $71.51 \pm 7.97$ & $-3.33 \pm 8.26$ & $<0.001$ & 0.850 \\
\hline
\end{tabular}

LBM lean body mass, DXA dual energy $\mathrm{X}$-ray absorptiometry, $S D$ standard deviation

for all tissues $(p<0.01)$ except for brain SUVmax. The dependency on BMI was eliminated when using either Dixon, James, or Janma-based SUVlean calculations resulting in non-significant correlation for most cases. Reduced dependence on BMI is also demonstrated by the reduced slope of linear regression shown in the scatter plot (supplementary material).

Coefficient of variance (CV) for all SUVlean measurements was smaller than that of SUVbw measurements, suggesting a smaller variance among patients. CV of SUV dixon, SUV_james, and SUV_janma measurements were comparable. The one-way ANOVA among the 4 SUVs methods showed that SUVbw was significantly different from all SUVlean measurements for all tissues $(p<0.001)$. Another ANOVA test among SUV_dixon, SUV_james, and SUV_janma also showed significant difference $(p$ $<0.001$ ), except for SUVmax of the brain where $p=0.052$.

\section{SUV in PSMA study}

The SUVbw's correlation with BMI was stronger than SUVlean for all tissues (Table 4). However, the correlation was significant only in the blood pool $(p=0.04)$ while not statistically significant within other organs. The dependency on BMI was eliminated after being corrected using the Dixon, James, or Janma-based SUVlean calculations as demonstrated by the reduced slope in supplementary material. One-way ANOVA showed significant difference between SUVlean measured using the Dixon method vs James and Janma models within normal organs. Quantitative statistics results are summarized in Table 4 and linear regression of PSMA SUVbw and SUVlean as a function of BMI is shown in supplementary material.

\section{Liver SUV among four BMI subgroups}

To further investigate whether obesity has an impact on SUV, we separated the 90 patients in the FDG study into four sub-groups according to BMI [34]: BMI $<18.5$ were in the underweight group $(n=13), 18.5<\mathrm{BMI}<25$ were in the normal group $(n=50)$, $25<\mathrm{BMI}<30$ were in the overweight group $(n=18)$, and BMI $>30$ were in the obese group $(n=9)$. As demonstrated in Fig. 5 , patients with larger BMIs have higher liver SUVbw and the difference is statistically significant. This positive correlation was mostly eliminated after LBM normalization. 
Table 3 Fitting results and dependent analysis of SUV vs. BMI for the FDG study ( $n=90)$

\begin{tabular}{|c|c|c|c|c|c|c|c|c|}
\hline & & & $\begin{array}{l}\text { Mean } \pm \\
\text { SD }\end{array}$ & $\mathrm{CV}$ & $\begin{array}{l}\text { Slope } \\
\text { with }\end{array}$ & $\begin{array}{l}\text { Correlation } \\
\text { with BMI }\end{array}$ & $\begin{array}{l}\text { Significance of correlation } \\
\text { with BMI }(p)\end{array}$ & $\begin{array}{l}\text { ANOVA } \\
(p)\end{array}$ \\
\hline \multirow[t]{8}{*}{ Brain } & Max & bw & $\begin{array}{l}20.69 \pm \\
8.86\end{array}$ & 0.428 & 0.417 & 0.173 & 0.103 & $\begin{array}{l}p< \\
0.001\end{array}$ \\
\hline & & Dixon & $\begin{array}{l}13.39 \pm \\
5.77\end{array}$ & 0.430 & 0.132 & 0.067 & 0.531 & 0.052 \\
\hline & & James & $\begin{array}{l}15.70 \pm \\
6.59\end{array}$ & 0.420 & 0.094 & 0.032 & 0.767 & \\
\hline & & Janma & $\begin{array}{l}14.68 \pm \\
6.28\end{array}$ & 0.427 & 0.128 & 0.061 & 0.567 & \\
\hline & Mean & bw & $\begin{array}{l}5.72 \pm \\
1.46\end{array}$ & 0.255 & 0.115 & 0.317 & 0.002 & $\begin{array}{l}p< \\
0.001\end{array}$ \\
\hline & & Dixon & $\begin{array}{l}3.71 \pm \\
0.97\end{array}$ & 0.260 & 0.037 & 0.143 & 0.178 & $\begin{array}{l}p< \\
0.001\end{array}$ \\
\hline & & James & $\begin{array}{l}4.34 \pm \\
1.04\end{array}$ & 0.239 & 0.024 & 0.078 & 0.465 & \\
\hline & & Janma & $\begin{array}{l}4.05 \pm \\
1.02\end{array}$ & 0.251 & 0.033 & 0.124 & 0.245 & \\
\hline \multirow[t]{8}{*}{ Liver } & Max & bw & $\begin{array}{l}1.89 \pm \\
0.37\end{array}$ & 0.196 & 0.043 & 0.536 & $p<0.001$ & $\begin{array}{l}p< \\
0.001\end{array}$ \\
\hline & & Dixon & $\begin{array}{l}1.22 \pm \\
0.23\end{array}$ & 0.187 & 0.015 & 0.316 & 0.002 & $\begin{array}{l}p< \\
0.001\end{array}$ \\
\hline & & James & $\begin{array}{l}1.43 \pm \\
0.24\end{array}$ & 0.165 & 0.010 & 0.211 & 0.046 & \\
\hline & & Janma & $\begin{array}{l}1.34 \pm \\
0.25\end{array}$ & 0.185 & 0.012 & 0.254 & 0.016 & \\
\hline & Mean & bw & $\begin{array}{l}1.59 \pm \\
0.28\end{array}$ & 0.179 & 0.029 & 0.454 & $p<0.001$ & $\begin{array}{l}p< \\
0.001\end{array}$ \\
\hline & & Dixon & $\begin{array}{l}1.03 \pm \\
0.17\end{array}$ & 0.165 & 0.008 & 0.217 & 0.04 & $\begin{array}{l}p< \\
0.001\end{array}$ \\
\hline & & James & $\begin{array}{l}1.21 \pm \\
0.19\end{array}$ & 0.159 & 0.003 & 0.079 & 0.459 & \\
\hline & & Janma & $\begin{array}{l}1.13 \pm \\
0.20\end{array}$ & 0.176 & 0.005 & 0.143 & 0.180 & \\
\hline \multirow[t]{8}{*}{ Blood } & Max & bw & $\begin{array}{l}1.02 \pm \\
0.20\end{array}$ & 0.192 & 0.019 & 0.402 & $p<0.001$ & $\begin{array}{l}p< \\
0.001\end{array}$ \\
\hline & & Dixon & $\begin{array}{l}0.66 \pm \\
0.11\end{array}$ & 0.162 & 0.005 & 0.189 & 0.074 & $\begin{array}{l}p< \\
0.001\end{array}$ \\
\hline & & James & $\begin{array}{l}0.77 \pm \\
0.13\end{array}$ & 0.171 & 0.002 & 0.056 & 0.603 & \\
\hline & & Janma & $\begin{array}{l}0.72 \pm \\
0.13\end{array}$ & 0.186 & 0.004 & 0.114 & 0.283 & \\
\hline & Mean & bw & $\begin{array}{l}0.90 \pm \\
0.19\end{array}$ & 0.207 & 0.014 & 0.306 & 0.003 & $\begin{array}{l}p< \\
0.001\end{array}$ \\
\hline & & Dixon & $\begin{array}{l}0.58 \pm \\
0.10\end{array}$ & 0.176 & 0.003 & 0.093 & 0.382 & $\begin{array}{l}p< \\
0.001\end{array}$ \\
\hline & & James & $\begin{array}{l}0.69 \pm \\
0.13\end{array}$ & 0.189 & 0.000 & -0.024 & 0.822 & \\
\hline & & Janma & $\begin{array}{l}0.64 \pm \\
0.13\end{array}$ & 0.197 & 0.001 & 0.039 & 0.714 & \\
\hline \multirow[t]{3}{*}{ Muscle } & Max & bw & $\begin{array}{l}0.65 \pm \\
0.16\end{array}$ & 0.253 & 0.016 & 0.426 & $p<0.001$ & $\begin{array}{l}p< \\
0.001\end{array}$ \\
\hline & & Dixon & $\begin{array}{l}0.42 \pm \\
0.09\end{array}$ & 0.220 & 0.006 & 0.280 & 0.008 & $\begin{array}{l}p< \\
0.001\end{array}$ \\
\hline & & James & $0.49 \pm$ & 0.220 & 0.005 & 0.189 & 0.074 & \\
\hline
\end{tabular}


Table 3 Fitting results and dependent analysis of SUV vs. BMI for the FDG study ( $n=90)$ (Continued)

\begin{tabular}{|c|c|c|c|c|c|c|c|}
\hline & & $\begin{array}{l}\text { Mean } \pm \\
\text { SD }\end{array}$ & $\mathrm{CV}$ & $\begin{array}{l}\text { Slope } \\
\text { with }\end{array}$ & $\begin{array}{l}\text { Correlation } \\
\text { with BMI }\end{array}$ & $\begin{array}{l}\text { Significance of correlation } \\
\text { with BMI }(p)\end{array}$ & $\begin{array}{l}\text { ANOVA } \\
(p)\end{array}$ \\
\hline & & 0.11 & & & & & \\
\hline & Janma & $\begin{array}{l}0.46 \pm \\
0.10\end{array}$ & 0.227 & 0.005 & 0.232 & 0.028 & \\
\hline \multirow[t]{4}{*}{ Mean } & bw & $\begin{array}{l}0.54 \pm \\
0.13\end{array}$ & 0.237 & 0.010 & 0.348 & $p<0.001$ & $\begin{array}{l}p< \\
0.001\end{array}$ \\
\hline & Dixon & $\begin{array}{l}0.35 \pm \\
0.07\end{array}$ & 0.196 & 0.003 & 0.182 & 0.086 & $\begin{array}{l}p< \\
0.001\end{array}$ \\
\hline & James & $\begin{array}{l}0.41 \pm \\
0.08\end{array}$ & 0.207 & 0.002 & 0.077 & 0.468 & \\
\hline & Janma & $\begin{array}{l}0.38 \pm \\
0.08\end{array}$ & 0.211 & 0.002 & 0.126 & 0.237 & \\
\hline
\end{tabular}

SUV standardized uptake value, BMI body mass index, $C V$ coefficient of variation, DXA dual energy X-ray absorptiometry, $S D$ standard deviation, ANOVA analysis of variance

\section{Discussion}

Quantitation of tracer uptake from PET/MR images is essential for cancer staging and treatment response evaluation in both clinical and research settings. The pitfall of the widely used SUVbw is that it is highly dependent on patient weight and may overestimate the uptake in obese patients [5]. It has been reported that SUVbw was 70\% higher in high-weight patients than in low-weight patients, and the overestimation was reduced when using other SUV normalization factors [35]. Using LBM instead of full body weight can effectively eliminate this effect and improve consistency among patients. Our findings in the FDG study were consistent to those reported by Zasadny [5] and Wahl $[8,12]$. Our findings in the PSMA study were also in line with previously reported results [36, 37]. However, it is notable that, even though the multiple approaches all achieved satisfactory correction for the BMI dependency of SUV, significant differences were found among the Dixon, James, and Janma approaches.

Using DXA as the reference standard, this study compared, for the first time, the accuracy of these three widely used approaches to estimate LBM. All three methods were found to be in good agreement with DXA, with Dixon offering the smallest bias due to its direct measurement of body composition. The James and Janma models might be prone to individual bias due to the fact that BMI might not be fully indicative of body fat content, even though they both offer reasonable population-based estimates of body fat content in the recruited cohorts from our study.

The Dixon approach offers quantitative measurement of the water/fat volume from MRI images and has gradually established itself as an alternative LBM standard [23]. Jochimsen et al. [22] first proposed a method to correct SUV using the water/fat fraction from Dixon scans in 2015. In the present work, we revised their method to be more straight-forward and easy-to-implement and validated it using a larger patient cohort and an additional tracer. Our method is different from Jochimsen's in that we utilized DXA measurements to transfer volume units into mass units, whereas they used signal intensity fraction instead.

It is notable that in previous reports, both body weight and BMI can be utilized as the dependent variable for SUV when evaluating the impact of obesity on SUV accuracy. We used BMI as the factor reflecting patient adiposity in our study because it is 
Table 4 Fitting results and dependent analysis of SUV vs BMI for the PSMA study $(n=28)$

\begin{tabular}{|c|c|c|c|c|c|c|c|c|}
\hline & & & Mean \pm SD & $\mathrm{CV}$ & $\begin{array}{l}\text { Slope } \\
\text { with } \\
\text { BMI }\end{array}$ & $\begin{array}{l}\text { Correlation } \\
\text { with BMI }\end{array}$ & $\begin{array}{l}\text { Significance } \\
\text { of } \\
\text { correlation } \\
\text { with BMI }(p)\end{array}$ & $\begin{array}{l}\text { ANOVA } \\
(p)\end{array}$ \\
\hline \multirow[t]{8}{*}{ Liver } & Max & bw & $8.85 \pm 2.40$ & 0.271 & 0.167 & 0.189 & 0.336 & $p<0.001$ \\
\hline & & Dixon & $5.97 \pm 1.45$ & 0.243 & 0.024 & 0.044 & 0.822 & 0.058 \\
\hline & & James & $6.96 \pm 1.81$ & 0.260 & 0.022 & 0.033 & 0.866 & \\
\hline & & Janma & $6.87 \pm 1.77$ & 0.258 & 0.010 & 0.016 & 0.938 & \\
\hline & Mean & bw & $7.06 \pm 2.04$ & 0.289 & 0.148 & 0.197 & 0.316 & $p<0.001$ \\
\hline & & Dixon & $4.75 \pm 1.24$ & 0.260 & 0.032 & 0.070 & 0.725 & 0.080 \\
\hline & & James & $5.55 \pm 1.55$ & 0.279 & 0.032 & 0.056 & 0.776 & \\
\hline & & Janma & $5.47 \pm 1.52$ & 0.277 & 0.023 & 0.041 & 0.837 & \\
\hline \multirow[t]{8}{*}{ Parotid } & Max & bw & $19.90 \pm 5.62$ & 0.283 & 0.208 & 0.101 & 0.611 & $p<0.001$ \\
\hline & & Dixon & $13.51 \pm 3.93$ & 0.291 & 0.004 & 0.003 & 0.990 & 0.120 \\
\hline & & James & $15.66 \pm 4.44$ & 0.283 & -0.054 & -0.033 & 0.867 & \\
\hline & & Janma & $15.45 \pm 4.37$ & 0.283 & -0.076 & -0.047 & 0.812 & \\
\hline & Mean & bw & $10.32 \pm 2.72$ & 0.264 & -0.054 & -0.053 & 0.787 & $p<0.001$ \\
\hline & & Dixon & $7.02 \pm 1.95$ & 0.278 & -0.113 & -0.158 & 0.422 & 0.101 \\
\hline & & James & $8.13 \pm 2.22$ & 0.273 & -0.157 & -0.192 & 0.329 & \\
\hline & & Janma & $8.03 \pm 2.19$ & 0.273 & -0.166 & -0.206 & 0.293 & \\
\hline \multirow[t]{8}{*}{ Blood } & Max & bw & $0.72 \pm 0.23$ & 0.325 & 0.033 & 0.389 & 0.041 & $p<0.001$ \\
\hline & & Dixon & $0.49 \pm 0.15$ & 0.318 & 0.017 & 0.298 & 0.124 & 0.166 \\
\hline & & James & $0.56 \pm 0.17$ & 0.302 & 0.017 & 0.267 & 0.169 & \\
\hline & & Janma & $0.56 \pm 0.17$ & 0.300 & 0.016 & 0.252 & 0.195 & \\
\hline & Mean & bw & $0.54 \pm 0.20$ & 0.368 & 0.016 & 0.218 & 0.265 & 0.001 \\
\hline & & Dixon & $0.37 \pm 0.14$ & 0.371 & 0.006 & 0.129 & 0.514 & 0.266 \\
\hline & & James & $0.42 \pm 0.15$ & 0.360 & 0.006 & 0.104 & 0.600 & \\
\hline & & Janma & $0.42 \pm 0.15$ & 0.359 & 0.005 & 0.092 & 0.644 & \\
\hline \multirow[t]{8}{*}{ Muscle } & Max & bw & $0.52 \pm 0.18$ & 0.351 & 0.009 & 0.129 & 0.513 & $p<0.001$ \\
\hline & & Dixon & $0.35 \pm 0.12$ & 0.334 & 0.001 & 0.031 & 0.878 & 0.198 \\
\hline & & James & $0.41 \pm 0.14$ & 0.347 & 0.001 & 0.009 & 0.964 & \\
\hline & & Janma & $0.40 \pm 0.14$ & 0.346 & 0.000 & -0.004 & 0.983 & \\
\hline & Mean & bw & $0.33 \pm 0.09$ & 0.280 & 0.010 & 0.293 & 0.130 & $p<0.001$ \\
\hline & & Dixon & $0.22 \pm 0.05$ & 0.249 & 0.004 & 0.201 & 0.304 & 0.064 \\
\hline & & James & $0.26 \pm 0.07$ & 0.266 & 0.004 & 0.149 & 0.449 & \\
\hline & & Janma & $0.25 \pm 0.07$ & 0.265 & 0.003 & 0.133 & 0.501 & \\
\hline \multirow[t]{8}{*}{ Prostate } & Max & bw & $14.0 \pm 10.92$ & 0.777 & 0.483 & 0.120 & 0.542 & 0.267 \\
\hline & & Dixon & $9.39 \pm 7.20$ & 0.767 & 0.200 & 0.075 & 0.703 & 0.709 \\
\hline & & James & $11.03 \pm 8.71$ & 0.790 & 0.200 & 0.062 & 0.753 & \\
\hline & & Janma & $10.88 \pm 8.61$ & 0.791 & 0.179 & 0.056 & 0.776 & \\
\hline & Mean & bw & $5.89 \pm 3.77$ & 0.639 & 0.190 & 0.137 & 0.487 & 0.143 \\
\hline & & Dixon & $3.99 \pm 2.67$ & 0.670 & 0.074 & 0.075 & 0.705 & 0.660 \\
\hline & & James & $4.63 \pm 3.00$ & 0.648 & 0.073 & 0.066 & 0.738 & \\
\hline & & Janma & $4.56 \pm 2.96$ & 0.649 & 0.064 & 0.059 & 0.768 & \\
\hline \multirow[t]{2}{*}{ Lesion } & Peak & bw & $4.53 \pm 2.33$ & 0.516 & 0.590 & 0.629 & 0.003 & 0.080 \\
\hline & & Dixon & $3.05 \pm 1.55$ & 0.507 & 0.357 & 0.575 & 0.008 & 0.655 \\
\hline
\end{tabular}


Table 4 Fitting results and dependent analysis of SUV vs BMI for the PSMA study $(n=28)$ (Continued)

\begin{tabular}{llllllll}
\hline & Mean \pm SD & CV & $\begin{array}{l}\text { Slope } \\
\text { with } \\
\text { BMI }\end{array}$ & $\begin{array}{l}\text { Correlation } \\
\text { with BMI }\end{array}$ & $\begin{array}{l}\text { Significance } \\
\text { of } \\
\text { correlation } \\
\text { with BMI }(\boldsymbol{p})\end{array}$ & $\begin{array}{l}\text { ANOVA } \\
(\boldsymbol{p})\end{array}$ \\
\hline \multirow{6}{*}{ Mean } & & & & & & 0.007 & \\
& James & $3.49 \pm 1.72$ & 0.493 & 0.403 & 0.583 & 0.007 & \\
& Janma & $3.44 \pm 1.69$ & 0.491 & 0.392 & 0.579 & 0.001 & 0.032 \\
& bw & $3.86 \pm 1.73$ & 0.448 & 0.463 & 0.666 & 0.005 & 0.565 \\
& Dixon & $2.60 \pm 1.15$ & 0.443 & 0.278 & 0.600 & 0.004 & \\
\hline & James & $2.98 \pm 1.28$ & 0.428 & 0.312 & 0.609 & 0.005 & \\
\hline
\end{tabular}

SUV, standardized uptake value; $B M I$, body mass index; $C V$, coefficient of variation; $D X A$, dual energy $X$-ray absorptiometry; SD, standard deviation; ANOVA, analysis of variance

more indicative of actual fat content than body weight. For instance, patients from our cohort exhibited a wide range of body sizes, but the most obese subject, with the highest BMI, was of moderate bodyweight $(80 \mathrm{~kg})$ but very short in height $(1.52 \mathrm{~m})$. Therefore, weight may not be an ideal parameter to indicate the degree of obesity and we used BMI $\left(\mathrm{BMI}=\right.$ weight $/$ height $\left.^{2}\right)$ as an indicator instead.

It is worthwhile mentioning that even though all three LBM approaches can be utilized to correct for the BMI dependency of SUV in FDG and PSMA studies, significant variation still exists among different approaches. A potential cause of this is that all empirical models including James and Janma are derived from specific patient populations while Dixon is a direct measurement of body composition. In serial PET/MR scans where quantitative accuracy is crucial, a consistent SUVlean calculation approach should be adopted, to minimize systematic bias, when correcting for the change of body weight and BMI index over time.

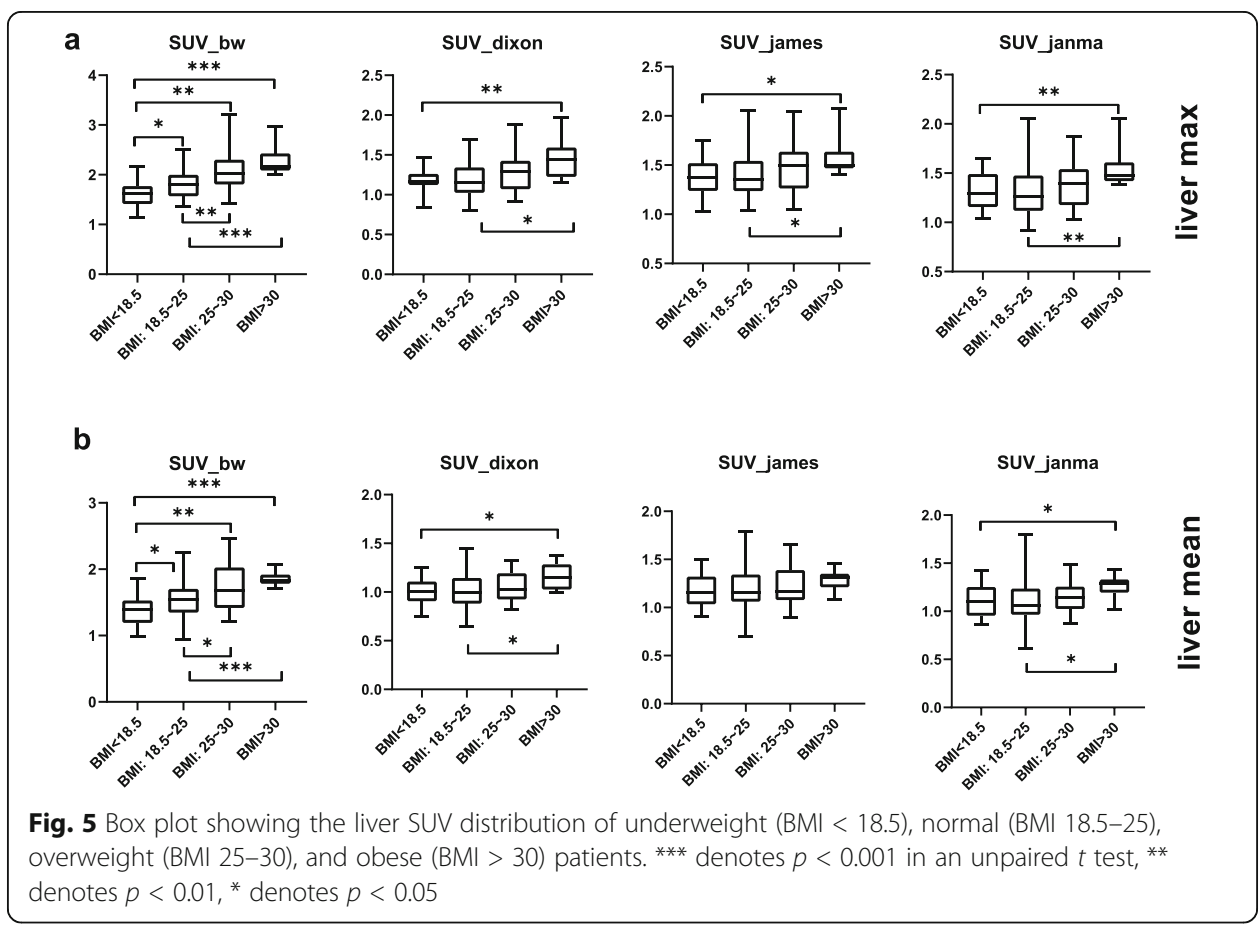


This study excluded patients with metal implants as they can induce severe imaging artifact in PET/MR [38], which could affect the image quality and qualitative results. Other imaging artifacts, such as motion, are minimized during the scan by asking the patients to breathe normally or hold breath during some of the MR sequences.

It is notable that statistically significant difference was found among SUV_lean calculations when using either the Dixon, James, or Janma methods in the FDG group. As the lean body weight derived from the Dixon images was found to be the most consistent with the DXA measurement, it indicates that the Dixon method might offer the most accurate correction factor for translating SUV_bw into SUV_lean for this particular patient cohort. However, Dixon is prone to multiple pitfalls caused by inherent limitations of the MRI acquisition (not full body) and image segmentation for the MRAC. One major challenge is that tissue characterization assumes uniform density for individual tissue type, but in real world clinical cases, such density might vary across different organs and patients. Both James and Janma equations were summarized based on large scale patient cohort in a western population; however, the validity of these empirical formulas for specific patient populations remains to be investigated.

There are a few limitations in this study. Firstly, since we were using 2-point Dixon which is the basic form of water fat imaging (WFI), we could only obtain the total amount of body fat by summing up the total number of categorized voxels. Further work might involve the use of more advanced WFI sequences (e.g., 6-point Dixon) that can differentiate different types of adipose tissue and derive the fat content within a single voxel. Brown adipose tissue that is typically active in glucose metabolism [39, 40] should not be subtracted from LBM. Secondly, although SUV dependency on BMI in the PSMA study was shown to be strong, the correlation between the SUV and BMI in most organs (except for blood pool) was not statistically significant. This could be due to the limited number of patients enrolled in this study. In a recent work by Grafita et al., a weak but significantly positive correlation was observed between liver SUV and body weight among 121 patients who underwent 68Ga-PSMA PET/CT. The SUVlean normalized to Janma LBM was reported to have a reduced correlation with body weight. Finally, the results of the lesion uptake were not in line with normal organs, possibly because lesions are heterogeneous in nature and subject to the specific biochemical differences between patients. The uptake of lesions depends mostly on characteristics of the tumor itself, such as tumor stage, size, degree of aggressiveness, and histology type.

\section{Conclusion}

In this study, we have compared LBM calculated using the Dixon, James, and Janma approaches and validated their accuracy against DXA measurements. All three methods offer good estimates of LBM with the Dixon method offering the best agreement with DXA. SUVbw was found to be positively correlated with BMI in the FDG and PSMA patient populations while SUVlean calculated using Dixon, James and Janma methods confirmed a decreased dependence on BMI. However, significant systematic variation was found among SUVlean calculations using different approaches, suggesting that a consistent correction method would be needed for $\mathrm{PET} / \mathrm{MR}$ serial scans. 


\section{Supplementary Information}

The online version contains supplementary material available at https://doi.org/10.1186/s40658-021-00363-w.

Additional file 1:. FDG

Additional file 2:. PSMA

\section{Acknowledgements}

We would like to thank the financial support from key research program (2016YFC0103900), Ministry of Science and Technology of People's Republic of China and Key Specialty Construction Project of Pudong Health and Family Planning Commission of Shanghai. We would also like to thank Dr. Adam Chandler from United Imaging America for proof-reading.

\section{Code availability}

Not applicable.

\section{Authors' contributions}

The authors read and approved the final manuscript.

\section{Funding}

Key Specialty Construction Project of Pudong Health and Family Planning Commission of Shanghai, PWZzk2017-24. Project of Science and Technology Commission of Shanghai Municipality, 19DZ1930703.

\section{Availability of data and materials}

Not applicable.

\section{Ethics approval and consent to participate}

All procedures performed in studies involving human participants were in accordance with the ethical standards of the institutional and/or national research committee and with the principles of the 1964 Declaration of Helsinki and its later amendments or comparable ethical standards. Informed consents were obtained from the patients for the anonymous use of their clinical, imaging, and histologic data for publication.

\section{Consent for publication}

Written informed consent for publication was obtained from all participants.

\section{Competing interests}

Qiaoyi Xue, Zhe Wang, Jianmin Yuan, Hui Liu, and Lingzhi Hu are the employees of United Imaging Healthcare. The other authors declare that they have no conflict of interest.

\section{Author details}

${ }^{1}$ Department of Nuclear Medicine, Shanghai East Hospital, Tongji University School of Medicine, Shanghai, China.

${ }^{2}$ Central Research Institute, United Imaging Healthcare Group, Shanghai, China.

Received: 4 November 2020 Accepted: 4 February 2021

Published online: 17 February 2021

\section{References}

1. Park SY, Zacharias C, Harrison CM, Fan RE, Kunder CA, Hatami N, et al. Gallium 68 PSMA-11 PET/MR imaging in patients with intermediate- or high-risk prostate cancer. Radiology. 2018:288:495-505. https://doi.org/10.1148/radiol.2018172232.

2. Hope TA, Fayad ZA, Fowler KJ, Holley D, Catana C. State of the art PET/MRI: applications and limitations - summary of the first ISMRM/SNMMI co-provided workshop on PET/MRI. J Nucl Med. 2019;60:jnumed.119.227231. doi:https://doi.org/1 0.2967/jnumed.119.227231.

3. Hoekstra CJ, Paglianiti I, Hoekstra OS, Smit EF, Postmus PE, Teule GJJ, et al. Monitoring response to therapy in cancer using [18F]-2-fluoro-2-deoxy-d-glucose and positron emission tomography: an overview of different analytical methods. Eur J Nucl Med. 2000;27:731-43. https://doi.org/10.1007/s002590050570.

4. Strauss LG, Conti PS. The applications of PET in clinical oncology. J Nucl Med. 1991;32:623-48. https://doi.org/10.1097/ 00004424-199104000-00018

5. Zasadny KR, Wahl RL. Standardized uptake values of normal tissues at PET with 2-[fluorine-18]-fluoro-2-deoxy-D-glucose: variations with body weight and a method for correction. Radiology. 1993;189:847-50. https://doi.org/10.1148/ra diology.189.3.8234714.

6. Wahl RL, Jacene H, Kasamon Y, Lodge MA. From RECIST to PERCIST: Evolving considerations for PET response criteria in solid tumors. J Nucl Med. 2009:50:122S-50S.

7. Narita A, Shiomi S, Katayama Y, Yamanaga T, Daisaki H, Hamada K, et al. Usefulness of standardized uptake value normalized by individual CT-based lean body mass in application of PET response criteria in solid tumors (PERCIST). Radiol Phys Technol. 2016;9:170-7.

8. Sugawara Y, Zasadny KR, Neuhoff AW, Wahl RL. Reevaluation of the standardized uptake value for FDG: variations with body weight and methods for correction1. Radiol. 1999. https://doi.org/10.1148/radiology.213.2.r99nv37521.

9. Menda Y, Bushnell DL, Madsen MT, Mclaughlin K, Kahn D, Kernstine KH. Evaluation of various corrections to the standardized uptake value for diagnosis of pulmonary malignancy. Nucl Med Commun. 2001;22:1077. https://doi.org/1 0.1097/00006231-200110000-00004. 
10. Lowe VJ, Fletcher JW, Gobar L, Lawson M, Kirchner P, Valk PE, et al. Prospective investigation of positron emission tomography in lung nodules. J Clin Oncol. 1998;16:1075. https://doi.org/10.1016/j.polymer.2011.04.018.

11. James WPT. Research on obesity. Nutr Bull. 1977. https://doi.org/10.1111/j.1467-3010.1977.tb00966.x.

12. Tahari A, Chien D, Azadi J, Wahl RL. Optimum lean body formulation for correction of standardized uptake value in PET imaging. J Nucl Med. 2014;55:1481-4. https://doi.org/10.2967/jnumed.113.136986.

13. Janmahasatian S, Duffull DSB, Ash S, Ward LC, Byrne NM, Green B. Quantification of lean bodyweight. Clin Pharmacokinet. 2005;44:1051-65. https://doi.org/10.2165/00003088-200544100-00004.

14. Halsne T, Müller EG, Spiten AE, Sherwani AG, Mikalsen LTG, Rootwelt-Revheim ME, et al. Comparison of SUL values in oncological 18F-FDG PET/CT: The effect of new LBM formulas. J Nucl Med Technol. 2018; jnmt.117.204586.

15. Hu HH, Chen J, Shen W. Segmentation and quantification of adipose tissue by magnetic resonance imaging. MAGMA. 2016;29:259-76. https://doi.org/10.1007/s10334-015-0498-z.

16. Ulbrich EJ, Nanz D, Leinhard OD, Marcon M, Fischer MA. Whole-body adipose tissue and lean muscle volumes and their distribution across gender and age: MR-derived normative values in a normal-weight Swiss population. Magn Reson Med. 2017. https://doi.org/10.1002/mrm.26676.

17. Karlsson A, Rosander J, Romu T, Tallberg J, Leinhard OD. Automatic and quantitative assessment of regional muscle volume by multiatlas segmentation using whole-body water-fat MRI. J Magn Reson Imaging. 2015;41. https://doi.org/10.1002/jmri.24726.

18. Chan T. Computerized method for automatic evaluation of lean body mass from PET/CT: comparison with predictive equations. J Nucl Med. 2012;53:130. https://doi.org/10.2967/jnumed.111.089292.

19. Kim WH, Kim CG, Kim D-W. Comparison of SUVs normalized by lean body mass determined by CT with those normalized by lean body mass estimated by predictive equations in normal tissues. Nucl Med Mol Imaging (2010). 2012; 46:182-8. https://doi.org/10.1007/s13139-012-0146-8.

20. Devriese J, Beels L, Maes A, Christophe VDW, Pottel H. Evaluation of CT-based SUV normalization. Phys Med Biol. 2016;61:6369.

21. Dixon T. W. Simple proton spectroscopic imaging. Radiology. 1984;153:189-94. https://doi.org/10.1148/radiology.153.1. 6089263.

22. Jochimsen T, Schulz J, Busse H. Lean body mass correction of standardized uptake value in simultaneous whole-body positron emission tomography and magnetic resonance imaging. Phys Med Biol. 2015;60:4651-64. https://doi.org/10.1 088/0031-9155/60/12/4651.

23. Rausch I, Rust P, Beyer T, et al. Reproducibility of MRI Dixon-based attenuation correction in combined PET/MR with applications for lean body mass estimation. J Nucl Med. 2016.

24. Vriens D, De Geus-Oei LF, Van Laarhoven HW, Timmer-Bonte JNH, Krabbe PFM, Visser EP, et al. Evaluation of different normalization procedures for the calculation of the standardized uptake value in therapy response monitoring studies. Nucl Med Commun. 2009;30:550. https://doi.org/10.1097/MNM.0b013e32832bdc80.

25. Decazes P, Metivier D, Rouquette A, Talbot JN, Kerrou K. A method to improve the semiquantification of 18F-FDG uptake: reliability of the estimated lean body mass using the conventional, low-dose CT from PET/CT. J Nucl Med. 2015.

26. Erselcan T, Turgut B, Dogan D, Ozdemir S. Lean body mass-based standardized uptake value, derived from a predictive equation, might be misleading in PET studies. Eur J Nucl Med Mol Imaging. 2003;29:1630-8. https://doi.org/10.1007/s00259-002-0974-3.

27. Mazess RB, Barden HS, Bisek JP, Hanson J. Dual-energy X-ray absorptiometry for total-body and regional bone-mineral and soft-tissue composition. Am J Clin Nutr. 1990:1106-12. https://doi.org/10.1093/ajcn/51.6.1106.

28. Devriese J, Beels L, Maes A, Van De Wiele C, Gheysens O, Pottel H, et al. Review of clinically accessible methods to determine lean body mass for normalization of standardized uptake values. 2015;60:1.

29. Webber CE. Reproducibility of DXA measurements of bone mineral and body composition: application to routine clinical measurements. New York: Springer; 2012.

30. Prior BM, Cureton KJ, Modlesky CM, Evans EM, Sloniger MA, Saunders M, et al. In vivo validation of whole body composition estimates from dual-energy X-ray absorptiometry. J Appl Physiol. 1997;83:623-30. https://doi.org/10.1152/ja ppl.1997.83.2.623.

31. Borga M, West J, Bell J, Harvey N, Romu T, Heymsfield S. Advanced body composition assessment: from body mass index to body composition profiling. J Investig Med. 2018;66:887-95. https://doi.org/10.1136/jim-2018-000722.

32. Neeland IJ, Grundy SM, Li X, Adams-Huet B, Vega GL. Comparison of visceral fat mass measurement by dual-X-ray absorptiometry and magnetic resonance imaging in a multiethnic cohort: the Dallas Heart Study. Nutr Diabetes. 2016;6: e221. https://doi.org/10.1038/nutd.2016.28.

33. Liu G, Cao T, Hu L, Zheng J, Pang L, Hu P, et al. Validation of MR-based attenuation correction of a newly released whole-body simultaneous PET/MR system. Biomed Res Int. 2019;2019:1-10. https://doi.org/10.1155/2019/8213215.

34. Gallagher D, Heymsfield SB, Heo M, Jebb SA, Murgatroyd PR, Sakamoto Y. Healthy percentage body fat ranges: an approach for developing guidelines based on body mass index. Am J Clin Nutr. 2000;72:694-701. https://doi.org/10.1093/ajcn/72.3.694.

35. Kim CK, Gupta NC, Chandramouli B, Alavi A. Standardized uptake values of FDG: body surface area correction is preferable to body weight correction. J Nucl Med. 1994;35:164-7. https://doi.org/10.1007/BF02940018.

36. Gafita A, Calais J, Franz C, Rauscher I, Wang H, Roberstson A, et al. Evaluation of SUV normalized by lean body mass (SUL) in 68Ga-PSMA11 PET/CT: a bi-centric analysis. EJNMMI Res. 2019;9:103. https://doi.org/10.1186/s13550-019-0572-z.

37. Sarikaya I, Albatineh AN, Sarikaya A. Re-visiting SUV-weight and SUV-lean body mass in FDG PET studies. J Nucl Med Technol. 2019;48. https://doi.org/10.2967/jnmt.119.233353.

38. Hargreaves B, Worters P, Pauly K, Pauly J, Koch K, Gold G. Metal-induced artifacts in MRI. Am J Roentgenol. 2011;197: 547-55. https://doi.org/10.2214/AJR.11.7364.

39. Virtanen KA, Lidell ME, Orava J, Heglind M, Westergren R, Niemi T, et al. Functional brown adipose tissue in healthy adults. N Engl J Med. 2009;360:1518-25. https://doi.org/10.1056/NEJMoa0808949.

40. Yeung HWD, Grewal RK, Gonen M, Schöder H, Larson SM. Patterns of (18)F-FDG uptake in adipose tissue and muscle: a potential source of false-positives for PET. J Nucl Med. 2003;44:1789-96.

\section{Publisher's Note}

Springer Nature remains neutral with regard to jurisdictional claims in published maps and institutional affiliations. 